\title{
FIRST YEAR COMMUNICATIONS CLASSES: APPLICATIONS OF CRITICAL EVALUATION OF INFORMATION IN A PROBLEM-BASED LEARNING FRAMEWORK
}

\author{
Kate Mercer ${ }^{l}$, Kari Weaver ${ }^{l}$, George Lamont ${ }^{1}$, and Christine Moffatt ${ }^{l}$ \\ ${ }^{l}$ University of Waterloo \\ kmercer@uwaterloo.ca, kdweaver@uwaterloo.ca, glamont@uwaterloo.ca, christine.moffatt@uwaterloo.ca
}

\begin{abstract}
Increasingly in an information-centric society, educational institutions must navigate ideological and pragmatic approaches to teaching how and where students find information used to make decisions. Engineering students' information-seeking needs must also navigate a variety of competing sources of information-their professors, the library, their peers, family and friends, and industry professionals. Undergraduate engineering students are faced with learning both fundamental engineering concepts and soft skills such as information seeking and communication. One approach to teaching information seeking and communication could be Problem-Based Learning (PBL), which is a teaching method focused on having groups use open-ended realworld problems as a context for learning new concepts. This paper will provide a summary of the current scope of literature around PBL, implications for sustainability, and contextualize it within the multidisciplinary context of library-focused interventions in first year communications courses.
\end{abstract}

Keywords: First-year, Education, Engineering communication, Pedagogy

\section{INTRODUCTION}

At the University of Waterloo, first-year engineering students take a communication-focused class in which they are taught a lesson addressing how to find engineeringfocused information. University of Waterloo communications courses developed a concerted effort to systematically incorporate direct instruction not only on how to find information, but also on critically evaluating the information they are finding. Taught through a discussion-based interactive lecture format, this lesson begins conceptually with the understanding that students are overwhelmed by the amount of information they must negotiate, and the context that many sources they use is non-academic in nature. By acknowledging that students will have to navigate a variety of sources (trade publications, blogs, and technical documents, etc.) where the students themselves need to make a judgement about the quality, we have begun to contextualize our teaching within a new way of guiding them towards being critical of and evaluating sources. Our approach ensures that these ideas are bound in a context of real-world problems and applications and through re-framing our approach to teaching students how to navigate information as a whole rather than the quickest means to an end.

As we move towards a more sustainable understanding of engineering, it is important to consider this as part of a sustainable information-based framework. Sustainability in engineering is defined as "...the process of using resources in a way that does not compromise the environment or deplete the materials for future generations" [27]. Applying the idea of sustainability to how engineering students are finding and communicating the information they use in their studies, co-ops, and eventual careers leads to expanding the core ideas of sustainability beyond its traditional frameworks. By embracing the idea that one must put back more than one takes in to include being inclusive of information, we can come to how we can teach sustainable information-seeking practices [18].

Ultimately how we teach engineering students to use information must support them in finding information that justifies not only their decisions but also the broader implications that using such information has on the world. Further, while information used for problem solving has been historically bounded, present information seeking is inherently unsustainable due to the absurd quantity of information and increasing inability to consistently identify good information sources. Building a better understanding of what information students' intake and how this influences how they conceptualize engineering problems and ultimately work towards solutions will help us to develop new ways of teaching information in a way that is feasible in this information landscape.

One challenge to this approach is a scarcity of conceptual and pedagogical models that integrate critical evaluation of information into engineering undergraduate courses. The understanding around how 
engineering students are finding, using, and sharing information must be deepened, and new pedagogical models must align with the broader undergraduate curriculum and ultimately professional codes of ethics. Pedagogical approaches aimed at developing key professional skills that support their development into engineers solving real life problems must be proactive in training them to work critically with information through research and practice.

Through its specificity, Problem-Based Learning (PBL) may offer significant value to first year engineering communication classes. Ultimately, as engineering increasingly navigates an interdisciplinary context, the information being gathered and disseminated cannot remain expositional or one directional and must integrate into the educational approaches adopted across the discipline. This work will present Problem-Based Learning (PBL) as a context (1) to use Critical Evaluation of Information as an approach for developing information-seeking skills needed by engineering students; (2) give a pedagogical practice to guide sustainable information-seeking behaviours; and (3) provide lessons learned from teaching Critical Evaluation of Information to engineering students in first year communication courses.

\section{LITERATURE REVIEW}

\subsection{Critical Evaluation of Information}

When students arrive in higher education classrooms, their information-seeking behaviours are often scaled for less complex problems that require fewer resources. Students have little experience finding or using scientific and technical literature, often due to reduced access to these resources in high schools, and everyday questions are handled exclusively by search engines like Google [22]. Google gives the impression that reliable information can be found on a single platform, often on the first page of search results, which leads students to feel overconfident in their abilities to find good quality information [17]. As engineering students' research needs expand to include academic sources and technical reports, their experiences of information overload can become a barrier to understanding or using those resources effectively [2] [5] [11]. If students continue to rely on non-academic searches to meet their information needs, then educators and librarians need to teach students how to be critical of information and their sources.

Critical appraisal is an approach that originates in the health disciplines, where the use of information for clinical decision-making is a core component of professional practice and research. Critical appraisal is a systematic process to determine the strengths and weaknesses of resources while ascertaining the applicability and validity of the content for new research or clinical tasks [30]. Traditional critical-appraisal tools teach students how to engage with scientific evidence by asking a series of questions to judge an article's trustworthiness, value, and relevance to the field [10]. This question-based approach aligns closely with information evaluation models used in informationliteracy instruction that already uses tools such as RADAR [16]. RADAR encourages students to evaluate articles based on the relevance of the information, the authority of the source, the date the information was published or updated, the appearance of the material, and the reason the information was created at all [16]. Critical Evaluation of Information (CEI) fundamentally builds on these evaluation practices, while taking into account contextual factors including disciplinary needs, societal influences, and professional contexts as practical influencers.

For first-year engineering students at Waterloo, this information analysis is framed as CEI, an approach that emphasizes the importance of acquiring the skills necessary to assess the validity of information found on Google, in published research, and in technical reports. For education to be effective, it must incorporate students' current abilities and continue to build on their existing knowledge base to prepare them for their future engineering careers. In this case, CEI shifts students toward a critical mindset that allows them to overcome their information overload and helps them assess information as professionals and as information consumers.

\subsection{Problem/Project-Based Learning}

Problem or Project-Based Learning (PBL) has long been viewed as an effective pedagogical approach within engineering curricula [4]. PBL emphasizes the use of representative, group-oriented, open-ended problems drawn from professional settings. This alignment between professional practice expectations and classroom approaches is of particular importance within engineering. Furthermore, PBL is known to train students simultaneously to think through problems and associated outcomes while helping them gain content knowledge within a given curriculum [10]. These foundational aspects of PBL, and the learning it engenders through student experience, are ideal when training students to think and act as professionals in a classroom setting.

While PBL is a demonstrated approach for training engineering students in the practices of working engineers, less emphasis has been placed on the types of problems that successfully achieve the educational aims of PBL or on explicitly training students to solve problems through modeling the approaches used by engineering professionals [23]. For success, PBL in the classroom environment must be a problem of sufficient difficulty to be interesting, pull from prior knowledge, allow for teamwork, and promote self-directed learning 
while requiring critical reasoning and creative thinking to resolve within real world contexts [23]. Engineering students who engage regularly in PBL show improvement in their engineering knowledge and broader professional skill development beyond those engendered by the traditional engineering curriculum [8] [29].

Students also react positively to the integration of PBL in classroom spaces, provided it is well structured and that the problems are perceived as applicable to the topic of study. PBL can help students understand the need for an optimal, rather than maximal, design for problems [20]; enhance their motivation to learn and gain knowledge [9]; and perceive that they learn more about the problem than students not afforded the benefit of a PBL approach to learning [19]. Furthermore, PBL aids students in their interdisciplinary understanding of the complexities inherent in design problems by naturally requiring considerations of context, use, and cultural influences in the PBL process [15].

\section{PROBLEM-BASED LEARNING AS A PEDAGOGY FOR CRITICAL EVALUATION OF INFORMATION}

Traditional framing of information seeking highlights the need to frame the act around a clear and focused question, ultimately using the initial information that is found to validate, contextualize, and deepen the question. This is done to develop search terms that are inclusive and able to find the right information to answer the question, but also that align with traditional academic forms of knowledge. These are primarily subscription databases or tools that are available institutionally through libraries, and in many cases not available in professional contexts. For students, this is especially apt as professional contexts include summer jobs, internships, and co-op positions, where students are often not taught how and where to find information, but rather encouraged to simply Google something [14].

While there may be a right and wrong with calculations, the majority of information lives in an uncomfortable place that is largely guided by context. Students need a clear method of evaluating information that values both academic and other sources with acknowledged rigor as well as evaluating information that is non-academic. By using a metric that evaluates information gleaned from peers, mentors, and colleagues in parallel to academic sources, we can teach students to engage with the idea that information itself is shaping problem spaces, rather than providing a linear path toward an objective solution. Critical Evaluation of Information stems from health-focused critical appraisal frameworks. Critical appraisal in health uses systematic processes to identify strengths and weaknesses of research, while identifying how the research can apply to a specific clinical task [30]. CEI takes ideas from critical appraisal and uses existing information literacy tools to provide similar systematic processes to contextualize information as a whole. This moves the emphasis from where information is found to what information communicates and how it might be used with a problem.

Once information seeking and use are reconceptualized as a tool, and one linked intimately to problem iteration and solving, it becomes a core learning task with the PBL framework, and one that must be accounted for within the pedagogy. Within existing approaches to PBL, CEI can be emphasized as an initial step to gain content knowledge around the particulars of a problem and the cultural and social context. By understanding the influences that guide answers to potential solutions, we can build greater awareness of the complexities that permeate engineering questions. Information also becomes crucial as students iteratively work to think through problems and identify possible pathways especially within the team-based communication approaches that require a diversity of ideas and perspectives. By using CEI, we can better acknowledge information as coming from diverse sources, ultimately mirroring approaches used by practicing engineers for information seeking but acknowledging that students do not currently have the same mental models more experienced engineers do [18].

\subsection{Case Study: Engineering Communications}

Engineering students at the University of Waterloo first-year communications classes take engineeringcommunication courses, with a typical enrollment of roughly 25 students. The course focuses on technical communication, writing for multiple audiences, genres of engineering communication documents, research skills, persuasive communication, and oral-presentation skills. As part of the course's learning objectives about research skills, early in the semester a librarian comes to each class to give a lecture about CEI. The classes themselves are largely discussion-based, focusing on having students self-reflect on the sources they currently use and how those practices unintentionally guide their academic information seeking.

To effectively provide students with the opportunity for active learning after the interactive class discussion, students are given the opportunity to find two separate sources that can help inform their PBL-based course project — one traditionally academic using library resources, and the other from grey literature. By using the CEI approach students are introduced to the idea that information is a reflection of the society and individuals who created it. This means that different information is appropriate in various contexts, but more specifically the information one chooses to use needs to be assessed not just for appropriateness, but also contextualized within the intention in which it will be used for. Students are given roughly 20 minutes to find the two sources and complete 
a RADAR activity to evaluate them critically. RADAR is a framework that requires students to evaluate information sources by using a series of questions about the relevance, authority, date, appearance, accuracy, and reason behind the information [16]. By doing this after discussing the context, students are implicitly encouraged to use whatever source they want - Wikipedia, blogs, academic journals.

After completing the activity, the class returns for a discussion of what they found. We emphasize asking them what surprised them: what was hard? What information took longer to validate than expected? How could you tell if a source was ultimately good? Did students read academic sources beyond the abstract - and how did they feel about reading peer-reviewed articles? As the discussion progresses, the goal is to validate the process to find information students already use but encourage them to take steps beyond when it comes to being critical of sources. Ultimately, our goal is to show them that while on paper it may be faster to just Google something, it takes significant time to properly critically evaluate [14]. We intentionally ask them to go through the same process for academic and non-academic sources. If they cannot deeply understand the academic source they choose to use, they may also spend significant time trying to find the information that will help them contextualize a source. CEI ultimately has a goal of being critical of all information sources, regardless of type, and is focused on building skills that guide contextualizing information within a more specific context, relevant to engineering students as when they are professionals they often do not use academic sources.

Critical evaluation then becomes an integral part of the communication course and its deliverables and continues to be evaluated through the research and predesign process. Students employ CEI and the RADAR activity about one source as part of the project pitch made shortly after the librarian's session. The instructor has the option to select the project topic or allow students to pursue their interests, but each student must identify a problem and evaluate a source critically to begin the project and receive feedback. The pitch can also be the topic of an oral presentation, which invites class feedback about the problem analysis and engages critical evaluation of information with an audience of peers. After working on the project for approximately three weeks, students submit a progress report with an annotated bibliography in which students evaluate additional sources critically and justify their use of the sources in their project. An annotated bibliography can be given as a separate task as well. These stages allow the instructor to observe and refine students' critical evaluation of information.

When students complete a final recommendation report or proposal in the course, they are directed to include a brief assessment of the credibility and value of every source; the course gives students fewer explicit guidelines about how to assess information so that instructors can observe how students internalize and prioritize their information-evaluation practices. These iterations of CEI acculturate the students to assess sources as they explore topics with increasing independence, while making students accountable for their choices and giving them access to multiple iterations of guidance. As a result, critical evaluation of information becomes an inextricable part of problem-based learning and benefits from its potential for student engagement.

\section{DISCUSSION}

Framing information seeking as a way to find sources that are only academic in nature inherently distances the activity in the classroom from students' lived experiences in gathering and contextualizing information. Presenting information in a linear and tightly controlled way devalues the sources students' value, sidelines lived experiences, and teaches them there is a right and wrong, when information is inherently ambiguous [24]. This is not to diminish the value of academic or peer-reviewed sources - the value they have is significant. Our argument is that while students are building up a knowledge base, traditional academic sources can be perceived to be out of reach or intimidating. Students feel comfortable working with textbooks because they are aimed at a specific audience aimed at their current comprehension level. Peer-reviewed journal papers are written with the expectation that the intended audience possesses sufficient background understanding that allows them to comprehend, synthesize, and ultimately apply the information into the context necessary.

When students are faced with information they feel is beyond them, they often end up either bluffing their way through it, or moving to a source they better understand [7]. The goal of broadening our teaching of information seeking to include such sources is ultimately aimed at meeting them where they are. By grounding our approach within a student-focused context, we are able to move them towards the same end goal-using strong and rigorous information and emphasizing the importance of using evidence to make decisions. Problem-Based Learning (PBL) is a promising pedagogical strategy for the integrated teaching of CEI as it similarly meets students where they are, draws from their learned experiences, and develops skill sets around teamwork in classroom settings.

When considering how practicing engineers find, use, and communicate information across teams to solve problems, linking CEI to the PBL curriculum in the classroom environment in an intentional manner becomes crucial to student success [1]. Integrating that within a classroom becomes important to students' learned adaptations first in the classroom, then professionally, where it is not just about the output, it's about what they 
bring to the problem [13]. How they use and synthesize information effectively, efficiently, and accurately has a significant impact on problem solving - the better the information they have is, the more successful their problem solving will be [3].

Though PBL is pulling from real-world problems and building on prior knowledge, there is little attention in the literature to the information-seeking tasks required to identify and synthesize possible courses of action to any given problem. The existing literature on PBL has a significant hole in that it does not directly address information gathering and synthesis tasks. The literature recognizes the need for critical thinking and reasoning but there is not weight given to how students are finding and generating ideas - which largely are coming through informal information seeking (peers, blogs, Reddit, colleagues, mentors, social media, etc.) [14]. We know students are doing this, but we do not consider how we train students in this as well as training them to find traditionally academic sources (journals, textbooks, standards, etc.).

Within the PBL model, we provide students with a problem and expect an outcome. Students entering into undergraduate engineering programs need specific training and are in the process of building the skills and knowledge they need to become practicing engineers, but the fact that they do not, and in fact should not yet have these skills around information, is something that is not specifically outlined in existing pedagogy, or often explicitly in practice [14]. By implicitly guiding students towards information as a means to an end, we miss an opportunity to engage them at a critical point in their education, making this practice a habit and ultimately making the transition to professional life easier.

\subsection{Implications for Sustainability}

Sustainability is inherently complex and in no small part tied to the guiding standard of the Western modern world. Implicitly tied to this is the idea that much of engineering and information seeking is at its core founded on ideals that are not inclusive and are focused on advancement often at the expense of the environment and non-Western worldviews [25] [28]. We must begin to contextualize information within a framework of sustainability as well [12]. By designing informationseeking practices that inherently de-value and diminish perspectives and contexts that are not peer-reviewed, as educators we miss an opportunity to create a set of student information-seeking practices that are truly sustainable and inclusive of different lived experiences, contexts, and understandings [21]. It is easy to make this comparison as a one-to-one valuation of using 'professional' sources (white papers, technical documents), but we must begin to be self-critical when it comes to using all of the sources that can make engineering more sustainable (lived experiences, blogs, oral traditions) [25].
The idea of critically evaluating information and making these practices truly sustainable is an easy pedagogical fit with Problem-Based Learning (PBL) [26]. By using open-ended problems from diverse perspectives and situations, we are able to train students both how to effectively seek information and-perhaps more importantly - to consider how the information they use to guide their thinking can have lasting implications. Furthermore, by integrating CEI as a core component of PBL pedagogy, we can push students toward unfamiliar ways of knowing, communicating, and exposing themselves to unfamiliar and uncomfortable problem spaces and solutions. The very act of moving engineering students out of their comfort zones and enabling them to contextualize problems through information seeking and use, so long as it is conceptualized in the broadest sense of the terms, will ultimately help them make decisions around practice that begin to move towards true sustainabilitythat is to say that one puts back more into the earth than one takes out [6] [25].

\section{CONCLUSION}

The authors acknowledge this is not an easy or small approach to consider-the principles of teaching information seeking were designed with the intention of providing rigour and depth. Ultimately, if we guide students to information that is in itself overwhelming, either by type or amount, how can they be expected to find information that allows them to be sustainable in their professional practice? Problem-Based Learning (PBL) was intended to give students safe exposure to real-world problems while providing training in the approaches needed to successfully resolve them: sustainable information seeking begets sustainable design and practice. By connecting these concepts into a holistic, deliberate pedagogical approach, engineering educators have a unique opportunity to enhance student learning, ensure student information behaviours develop that mirror professional practice, and enable sustainability.

\section{References}

[1] Suzie Allard, Kenneth J. Levine, and Carol Tenopir, "Design engineers and technical professionals at work: Observing information usage in the workplace," Journal of the American Society for Information Science and Technology, vol. 60, no. 3., pp. 443-454, 2009.

[2] David Bawden, Clive Holtham, and Nigel Courtney, "Perspectives on information overload," Association for Information Management (ASLIB) Proceedings, vol. 51, no. 8, pp. 249-255, 1999. doi:10.1108/EUM0000000006984.

[3] Charles L. Citroen, "The role of information in strategic decision-making," International Journal of Information Management, vol. 31, no. 6, pp. 493-50, 2011. 
[4] Erik De Graaf, \& Anette Kolmos, "Characteristics of problem-based learning," International Journal of Engineering Education, vol. 19, no. 5, pp. 657-662, 2003.

[5] Angela Edmunds and Anne Morris, "The problem of information overload in business organisations: A review of the literature," International Journal of Information Management, vol. 20, no. 1, pp. 17-28, 2000. doi:10.1016/S02684012(99)00051-1.

[6] Arturo Escobar, "Sustainability: Design for the pluriverse," Development, vol. 54, no. 2, pp. 137-140, 2011.

[7] W. C. D. K. Fernando and R. M. P. S. Bandara, "Reading as a learning strategy for engineering undergraduates," Innovations in Education and Teaching International, pp. 1-10, 2020.

[8] Benoit Galand, Mariane Frenay, and Benoit Raucent, "Effectiveness of problem-based learning in engineering education: A comparative study on three levels of knowledge structure," International Journal of Engineering Education, vol. 28, no. 4, pp. 939-947, 2012.

[9] Roger G. Hadgraft and Anette Kolmos, "Emerging learning environments in engineering education," Australasian Journal of Engineering Education, vol. 25, no. 1, pp. 3-16, 2020. doi: $10.1080 / 22054952.2020 .1713522$

[10] Cindy E. Hmelo-Silver, "Problem-based learning: What and how do students learn?," Educational Psychology Review, vol. 16, no. 3, pp. 235-266, 2004.

[11] P. Ingwersen, "Cognitive perspectives of information retrieval interaction: elements of a cognitive IP theory," Journal of Documentation, vol. 52, no. 1, pp. 3-50, 1996.

[12] Thomas W. Jackson \& Pourya Farzaneh, "Theory-based model of factors affecting information overload," International Journal of Information Management, vol. 32, no. 6, pp. 523532, 2012. doi:10.1016/j.ijinfomgt.2012.04.006.

[13] Adam Kirn and Lisa Benson, (2018). 'Engineering students' perceptions of problem solving and their future," Journal of Engineering Education, vol. 107, no. 1, pp. 87-112, 2018.

[14] George Lamont, Kate Mercer, Kari Weaver, Rachel Figueiredo, Andrea Jonahs, Heather A. Love, Brad Mehlenbacher, Carter Neal, Katherine Zmetana, Rania AlHammoud. Information-seeking Behavior Among First-year Engineering Students and the Impacts of Pedagogical Intervention. Proceedings of the 2020 ASEE Conference. Montreal, Canada, 2020.

[15] Galyna Lutsenko, "Case study of a problem-based learning course of project management for senior engineering students," European Journal of Engineering Education, vol. 43, no. 6, pp. 895-910, 2018. doi: 10.1080/03043797.2018.1454892

[16] Jane Mandalois, "RADAR: An approach to helping students evaluate internet sources," Journal of Information Science, vol. 39, no. 4, pp. 470-478, 2013.

[17] Kathryn Mercer, Kari D. Weaver, Rachel Figueiredo, and Caitlin Carter, "Critical appraisal: The key to unlocking information literacy in the STEM disciplines," College \& Research Libraries News, vol. 81, no. 3, pp. 145-148, 2020. https://crln.acrl.org/index.php/crlnews/article/viewFile/24322/32 123

CEEA21; Paper 077

UPEI; June 20 - 23, 2021

-6 of $7-$
[18] Kate Mercer, Kari Weaver, George Lamont. Critical Appraisal \& Evaluation of Information. Science + SciComm + Work. Ed. Susan Rowland \& Louise Kuchel. Forthcoming, Springer Nature, 2021.

[19] Lidón Moliner, Luis Cabedo, Marta Royo, Jose GámezPérez, Pablo LopezCrespo, Mercè Segarra, and Teresa Guraya, "On the perceptions of students and professors in the implementation of an inter-university engineering PBL experience," European Journal of Engineering Education, vol. 44, no. 5, pp. 726-744, 2019. doi: $10.1080 / 03043797.2018 .1498829$

[20] Frank Moti, Ilana Lavy, and David Elata, "Implementing the project-based learning approach in an academic engineering course," International Journal of Technology and Design Education, vol. 13, pp. 273-288, 2003.

[21] Cynthia F. Murphy*, David Allen, Braden Allenby, John Crittenden, Cliff I. Davidson, Chris Hendrickson, and H. Scott Matthews, "Sustainability in engineering education and research at us universities," Environmental Science \& Technology, vol. 43, no. 15, pp. 5558-5564, 2009.

[22] Heather Brody Perry, "Information literacy in the sciences: Faculty perception of undergraduate student skill," College \& Research Libraries, vol. 78, no. 7, pp. 964-977, 2017. https://doi.org/10.5860/crl.78.7.964

[23] Nachamma Sockalingam and Henk G. Schmidt, "Characteristics of effective problems," pp. 141-165, In Glen O'Grady et al. (Eds.) One Day, One Problem: An Approach to Problem Based Learning. New York, NY: Springer, 298 p. \{eISBN: 978-9814-02175-3\}

[24] Angela Sample, "Historical development of definitions of information literacy: A literature review of selected resources," The Journal of Academic Librarianship Volume, vol. 46, no. 2, p. 102116, 2020.

[25] Deborah Shields, Francesca Verga, and Gian A. Blengini, "Incorporating sustainability in engineering education," International Journal of Sustainability in Higher Education, vol. 15, no. 4, pp. 390-403, 2014.

[26] Anne Steinemann, (2003), "Implementing sustainable development through problem based learning: pedagogy and practice," Journal of Professional Issues in Engineering Education and Practice, vol. 129, no. 4, pp. 216-225, 2003.

[27] UNESCO Engineering Initiative. "Quality Engineering for Sustainability.” UNESCO, Bonn, DE, Feb. 2013.

[28] Ethelene Whitmire, "Epistemological beliefs and the information-seeking behavior of undergraduates," Library and Information Science Research, vol. 25, no. 2, pp. 127-142, 2003. 
[29] Aman Yadav, Dipendrea Subdei, Mary A. Lundeberg, and Charles A. Bunting, "Problem-based learning: Influence on students' learning in an electrical engineering course," Journal of Engineering Education, vol. 100, no. 2, pp. 253-280, 2011.

[30] Jane M. Young and Michael J. Solomon, "How to critically appraise an article," Nature Reviews Gastroenterology \&

Hepatology, vol. 6, no. 2, pp. 82-91, 2009. 